\title{
FERRAMENTAS E PLATAFORMAS EDUCOMUNICATIVAS E SUA DIVERSIDADE DIDÁTICA ${ }^{1}$ \\ EDUCOMMUNICATIVE TOOLS AND PLATFORMS AND THEIR DIDACTIC DIVERSITY
}

\section{Roberta Bastos Mathias², Valeria Iensen Bortoluzzi ${ }^{3}$ e Taís Steffenello Ghisleni ${ }^{4}$}

\section{RESUMO}

Nesse artigo, são evidenciadas as ferramentas educomunicativas que são alternativas eficientes para serem utilizadas como instrumento pedagógico. Assim, objetivou-se expor tais práticas educomunicativas, bem como a apresentação de plataformas de rede social utilizadas no contexto educacional; a descrição das características de ferramentas educomunicativas utilizadas em situações de ensino aprendizagem; e ainda, relatar exemplos de experiências aplicadas. Metodologicamente, utilizou-se uma pesquisa de cunho exploratório descritivo-qualitativo. Na abordagem teórica, foram utilizados autores como Soares (2002), Coscarelli (2003), Martín-Barbero (2009), Thompson (1998), entre outros. Concluiu-se que a multimodalidade presente nas linguagens oral, escrita, audiovisual e multimídia nas ferramentas e plataformas educomunicativas facilita a aprendizagem, fazendo com que o processo seja mais desafiador e sintonizado com a base sócio técnica e sociocultural de nossa sociedade, e por isso a importância de explorar tais recursos.

Palavras-chave: Abordagens pedagógicas, Educomunicação, Práticas.

\section{ABSTRACT}

In this article, educational tools that are efficient alternatives to be used as a pedagogical tool are highlighted. Therefore, the objective was to expose such educommunicative practices, as well as the presentation of social media platforms used in the educational context; the description of the characteristics of the educommunicative tools used in teaching-learning situations; and yet examples of successful experiences. Methodologically, a descriptive-qualitative exploratory research was used. In the theoretical approach, authors such as Soares (2002), Coscarelli (2003), Martin-Barbero (2009), Thompson (1998), among others, were used. It was concluded that the multimodality present in oral, written, audiovisual and multimedia languages in educommunication tools and platforms facilitates learning, making the process more challenging and in tune with the socio-technical and sociocultural bases of our society, and therefore therefore the importance of exploiting such resources.

Keywords: Pedagogical approaches, educomunicación, practices.

1 Trabalho de Pós-Graduação Stricto Sensu.

2 Graduada em Letras. Aluna do Curso de Mestrado em Ensino de Humanidades e Linguagens da Universidade Franciscana - UFN.

3 Doutora em Letras. Professora dos Cursos de Letras e do Mestrado em Ensino de Humanidades e Linguagens da Universidade Franciscana - UFN.

4 Doutora em Comunicação. Professora dos Cursos de Publicidade e Propaganda e do Mestrado em Ensino de Humanidades e Linguagens da Universidade Franciscana - UFN. 


\section{INTRODUÇÃO}

A influência dos meios comunicacionais na sociedade estimulou um aumento de pesquisas relacionadas à educação e comunicação, em união. Entretanto, o cruzamento entre mídia e educação leva cada vez mais ao âmbito dos estudos voltados à Educomunicação. Essa área é identificada como “[...] uma práxis social, que não se reduz apenas à aplicação das Tecnologias da Informação e Comunicação (TIC'S), e sim como um campo de intervenção social” (SOARES, 2012, p. 10).

Nessas intervenções, o modo de gestão da comunicação em seus diferentes espaços é de suma importância para a expressão e criatividade na sociedade atual. Em tais espaços, "a linguagem é capaz de se tornar o repositório objetivo de vastas acumulações de significados e experiências, que pode então preservar no tempo e transmitir às gerações seguintes" (BERGER; LUCKMANN, 2003, p. 57). Portanto, entende-se a linguagem como um sistema de várias significações que faz com que se reflitam, acumulem conhecimentos e assim, por meio da comunicação, transmitimos aos outros. Sob esse viés, a educomunicação age como um campo de interface nesse desempenho, pois

\footnotetext{
diante de uma mídia que se sente livre para produzir e divulgar o que convém ao tipo ao tipo de relação que mantém com o mercado, a educação se previne e cria programas de análise crítica das mensagens em circulação; por sua vez, a comunicação, desobrigada do ensino formal, não se furta em conduzir a formação de hábitos e valores de seus públicos, através do entretenimento e de uma publicidade especificamente dirigida ao segmento infanto juvenil. Em outras palavras, os campos da comunicação e da educação, simultaneamente e cada um a seu modo, educam e comunicam (SOARES, 2012, p. 13).
}

Nesse sentido, as ferramentas e plataformas educomunicativas são alternativas eficientes para serem utilizadas como instrumento pedagógico, tais como o Facebook, blogs, fanzines, infográficos, HQ's, entre outras. Entende-se por ferramentas educomunicativas materiais que contém “[...] complexos processos no qual as mensagens que chegam às audiências sofrem interferências de uma série de mediações (gênero, étnica, etárias, classe social etc.) permitindo ao aluno significar, dessignificar ou ressignificar os campos de sentidos" (GÓMEZ, 2014, p. 6). Desse modo, tais ferramentas oferecem possibilidades primordiais para o contexto escolar, como atualidade e diversificação de conteúdo, interdisciplinaridade, linguagem acessível e caráter documental dos fatos registrados, facilitando o processo de ensino e aprendizagem.

É necessário ressaltar que as práticas educomunicativas estão além do que simplesmente utilizar a mídia digital em uma atividade em que os alunos consideram prazerosa por estarem vinculados aos meios de comunicação, bem como os professores com o ideário de um trabalho bem feito por trazer esses meios para sua didática. Para que essas práticas tenham validez, o docente deve aproveitar as ferramentas e plataformas digitais que foram positivas em seu trabalho de pré-atividades, para então fazer as inferências necessárias nesse elemento mediador de ensino aprendizagem, pois 
propor-se educar para e com os meios de comunicação requer análises cuidadosas, portanto, permanentes. Cabe ao professor estimular a aprendizagem, que pode ser prazerosa, mas sem perder de vista a criticidade, já que conteúdos desses mesmos meios podem ser integrados a prática pedagógica como fonte de aprendizado (GAIA, 2001, p. 87).

Assim, a diversidade de gêneros e plataformas multimodais permite nas práticas avançar a leituras múltiplas e diversificadas, a partir da dimensão de inter-relações existentes na nossa cultura industrial.

Quanto à relação do ensino aprendizagem, elucida-se que "o ensino visa estimular, dirigir, incentivar, impulsionar o processo de aprendizagem dos alunos” (LIBÂNEO, 1994, p. 90). Ou seja, para que os alunos adquiram conhecimento e saiam do modo empírico e senso comum de ensino, é preciso que se estimule a aprendizagem sistemática, sendo o estudante estimulado ao conteúdo proposto. Nesses conteúdos, a diversidade multimodal é um fator que realça as representações, sendo então a multimodalidade uma "descentralização da linguagem como favorecedora da construção de sentido, um novo olhar sobre os papéis da linguagem, da imagem, do suporte, do layout, do desenho do documento etc." (GOMES, 2010, p. 24). São aspectos que valorizam a análise do texto numa perspectiva dotada de sentido. Ainda nesse viés, "é necessário compreender a linguagem como algo inerentemente interdisciplinar, pois acopla diferentes perspectivas dialógicas e dialéticas, semiotizando diferentes posturas e efeitos de sentidos condizentes com as novas vertentes de exigências do mundo líquido" (PEREIRA, 2018, p. 42). A linguagem, na própria interação social, leva a contraposição e contradição de ideias, o que passa a levar a outros caminhos e, nesse mundo líquido, tudo muda muito rapidamente e de forma imprevisível.

Nessa linha de repentinas mudanças, os usos dos meios de comunicação caracterizam-se "como um tipo distinto de atividade social que envolve a produção, a transmissão e a recepção de formas simbólicas e implica a utilização de recursos de vários tipos” (THOMPSON, 1998, p. 25). A comunicação abordada por Thompson é muito discutida e vai ao encontro das redes, ou seja, não leva em conta somente as tecnologias, mas por exemplo, também a escrita, já que mantém a comunicação e a dissemina através desses vários recursos. A partir do contexto exposto, surgiu o seguinte problema de pesquisa: como as ferramentas educomunicativas são usadas para otimizar situações de ensino aprendizagem?

Sendo assim, nosso objetivo geral é: expor práticas educomunicativas que são utilizadas para otimizar situações de ensino aprendizagem. Para tanto, será necessário: refletir a educomunicação na educação; descrever as características de ferramentas educomunicativas utilizadas em situações de ensino aprendizagem; relatar experiências realizadas.

\section{ASPECTOS METODOLÓGICOS}

Esta pesquisa é de cunho exploratório, de maneira que "dá ênfase à geração e o desenvolvimento de teorias que especificam o fenômeno e as condições para sua manifestação" (GASQUE, 2007, p. 85). 
Sendo assim, a descrição de plataformas e ferramentas educomunicativas permite a participação de sujeitos, na criação e alimentação de materiais, de modo a ser planejado de acordo com os interesses dos docentes, para posteriormente verificar as mediações da ação educomunicativa na escrita de seus alunos. A educomunicação apresenta em um de seus âmbitos metodológicos educar com a mídia e, ao produzir conteúdo informativo e reflexivo, fornece-se ajuda aos professores para possibilitar a prática da livre expressão, com o mérito maior de gerar conhecimento e desenvolver a participação cidadã.

Além disso, a educomunicação suscita a aprendizagem através da utilização de mídias e técnicas de comunicação, sob participação colaborativa e interdisciplinar e, para tanto adentra-se além de um cunho exploratório, o descritivo-qualitativo, a qual destaca-se como "uma investigação que se assume como particularística, debruçando-se sobre uma situação específica, procurando descobrir o que há nela de mais essencial e característico. (MARTINS, 2008, p. 16). Dessa forma, destacam-se aqui intervenções com propósitos óbvios de oportunizar a educomunicação e de reflexão sobre as ferramentas e seus processos. Para atingir os processos que permeiam a educomunicação, foram pesquisadas práticas elaboradas dentro e/ou fora da sala de aula, como a exposição de conteúdos midiáticos através de leitura/produção de diferentes gêneros textuais. No entanto, para a exploração de tais práticas, foram levados em considerações materiais exclusivos disponíveis no site Nova Escola, uma plataforma de apoio didático aos docentes em que, inclusive, são publicadas atividades que tiveram notoriedade, destaque relevante no processo de ensino aprendizagem, como também publicações em revistas e periódicos.

\section{A EDUCOMUNICAÇÃO}

No último meio século, dois campos de saberes fortaleceram-se, geraram provocação, e assim ganharam uma forma de singularidade. São os campos da Comunicação Social e Educação Escolar, pois as duas possuem características muito próximas, sendo que essa intersecção gerou um espaço mais amplo de construções: a Educomunicação.

O neologismo Educomunicação, que em princípio parece mera junção de Educação e Comunicação, na realidade, não apenas une as áreas, mas destaca de modo significativo um terceiro termo, a ação. É sobre ele que continua a recair a tônica quando a palavra é pronunciada, dando-lhe assim, ao que parece, um significado particularmente importante. Educação e/ou Comunicação - assim como a Educomunicação - são formas de conhecimento, áreas do saber ou campo de construções que têm na ação o seu elemento inaugural (SOARES, 2006, p. 3).

Assim, através de práticas novas, transversam-se saberes historicamente constituídos, promovendo a interlocução ou a conversa entre os que constroem e/ou se utilizam desses saberes. Em outro viés, Soares $(2014$, p. 23) sucinta que a educomunicação tem como função “[...] integrar às práticas educativas o estudo sistemático dos sistemas de comunicação [...]; criar e fortalecer ecossistemas 
comunicativos em espaços educativos [...]; e melhorar o coeficiente expressivo e comunicativo das ações educativas [...]”. Isto ressalta que o domínio da educomunicação, mais do que um objeto a ser investigado, é um campo de relação de e entre saberes. Em tempos atuais

conjunto de manifestações constatáveis nas dinâmicas de produção, circulação e consumo das mercadorias, em suas diferentes formas, precisa ser tratado sob perspectiva que reconheça a possibilidade de estarmos frente a mecanismos estruturantes da vida societária em nosso tempo. Equivale dizer, os fatores de instabilidade, rapidez, transitoriedade, efemeridade etc., que entram na normatização dos vínculos entre sujeitos e coisas, sujeitos com outros sujeitos, sujeito consigo, deixam de representar, apenas, um conjunto de aspectos a cruzarem as nossas relações cotidianas, passando a esclarecer formas de vida, mecanismos de ser e estar no mundo. A questão transcende, portanto, o simples indício de mudanças no desenho como as sociabilidades são ativadas nos espaços escolares, ou no reconhecimento de que as tecnologias promovem novos comportamentos, haja vista tratarmos de reconfigurações amplas nas estruturas culturais, sociais, psicológicas, até mesmo das habilidades físicas... (CITELLI, 2016, p. 4).

Em outras palavras, visto pelo âmbito educomunicacional, não bastante somente dinamizar uma aula, mas sim compor um conjunto de ambientes comuns, estereótipos e construções expressivas no intuito do educando identificar certo grau de compreensão das coisas, porém que não retire do interior de cada indivíduo as marcas estruturalmente assentadas na percepção prática de diferentes realidades em suas regras, normas e procedimentos.

É preciso refletir as estratégias que engajam a educomunicação, pois não é apenas ensinar a usar uma ferramenta ou criar métodos para usar no ensino e aprendizagem, pois isso seria uma apropriação instrumental dos processos comunicativos.

O propósito é, a partir da utilização dos meios técnicos, sejam eles quais forem, - do WhatsApp a fita cassete -, propiciar o uso consciente e crítico para buscar transformações no mundo. Isso não pode ser confundido com tecnofobia ou aversão às possibilidades oferecidas pelas novidades (CALIXTO, 2017, p. 43).

Nesse viés reflexivo, há de se ter a compreensão semântica e sintonizadora com a produção simbólica que faz parte do cotidiano dos educandos, isto é, um cenário comunicacional, pois a influência digital não veio para dar fim à literatura. Silva (2011, p. 2), aborda que a chegada da informática gerou essa tecnofobia, "revelando problemas e dificuldade de relacionar-se com a nova tecnologia, [...] e a diminuição da importância do uso da tecnologia". Por isso, é importante discutir, descrever e explorar as mídias, já que essas revelam a questão do comportamento do social geral. As ferramentas vindas das mídias digitais desempenharam influências diretas e indiretas no ato da criação e nas possibilidades de diálogo entre didáticas e as novas mídias, ou seja, são otimizadoras ao processo de ensino aprendizagem. 


\section{FERRAMENTAS EDUCOMUNICATIVAS OTIMIZADORAS DO ENSINO APREN- DIZAGEM}

O desconhecimento sobre a utilização e aplicação das ferramentas educomunicativas para com o processo ensino aprendizagem limita a ação dos gestores e docentes, minimizando o avanço da produção e propagação de conhecimento. É necessário imaginar e criar através da variedade de recursos destas ferramentas. Bueno (2011, p. 15), exemplifica que "na cultura atual a comunicação se move num mecanismo de três engrenagens: compartilhar informação, manter-se informado e influenciar outras pessoas”. Logo, a inteligência coletiva passa a ocupar espaço sendo impulsionada e dinamizada pelas Tecnologias de Informação e Comunicação, gerando diferentes cenários para o processo ensino ${ }^{5}$ aprendizagem ${ }^{6}$. Sob esse viés, nos subcapítulos a seguir, serão apresentadas de forma exploratória ferramentas educomunicativas, como o fanzine, infográfico, podcasts e HQ’s.

\section{O GÊNERO FANZINE E SUA EXPRESSÃO ARTÍSTICA}

Os fanzines são publicações relacionadas a uma determinada arte e representam o espaço da reflexão, da crítica e da experimentação, eles podem ser impressos, digitais ou artesanais. "A importância dos fanzines dá-se pela difusão, renovação, formação do público e criação de um espaço essencial de discussão sobre os quadrinhos como expressão artística" (BEZERRA et al., 2017, p. 6). É um texto que traz para a educação questões do cotidiano das pessoas, fazendo com que os alunos percebam nesse contexto maneiras de pensar em seu dia a dia as formas de se comunicar por meio de linguagens artísticas. A pedagogia da comunicação entrou como uma ferramenta de promoção da interação entre docentes e discentes.

"As temáticas abordadas nos fanzines são infinitas, indo do plano político, social, econômico até temas com relatos, como os fanzines pessoais" (SANTOS, 2016, p. 14). Em sua estrutura, eles podem ser em forma de história em quadrinhos, investigação jornalística, séries, músicas, educativos, entre outros. Este gênero ganha um caráter de expressão artística porque é uma boa opção para públicos variados, como quadrinistas, apreciadores de séries, escritores etc. ressignificarem seus conhecimentos por meio da linguagem" (ORLANDI, 2002, p. 78). Para se elaborar uma fanzine, deve-se respectivamente eleger um objeto cultural como fonte da produção, explorar as narrativas, analisar a produção, trabalhar com as referências, explorar as plataformas digitais de publicação, planejar a produção textual e organizar o material. Na imagem (1), observe um fanzine digital produzido com base na série "La Casa de Papel", por alunos do Ensino Fundamental II, como exercício da disciplina de Português.

\footnotetext{
5 Para Paulo Freire (2004, p. 14), "é muito mais do que puramente treinar o educando no desempenho de destrezas [...]". 6 Ocorre "na medida em que se busca comunicação, integração a partir da comunicação com os demais. Não há educação sem amor" (FREIRE, 2014, p. 36).
} 


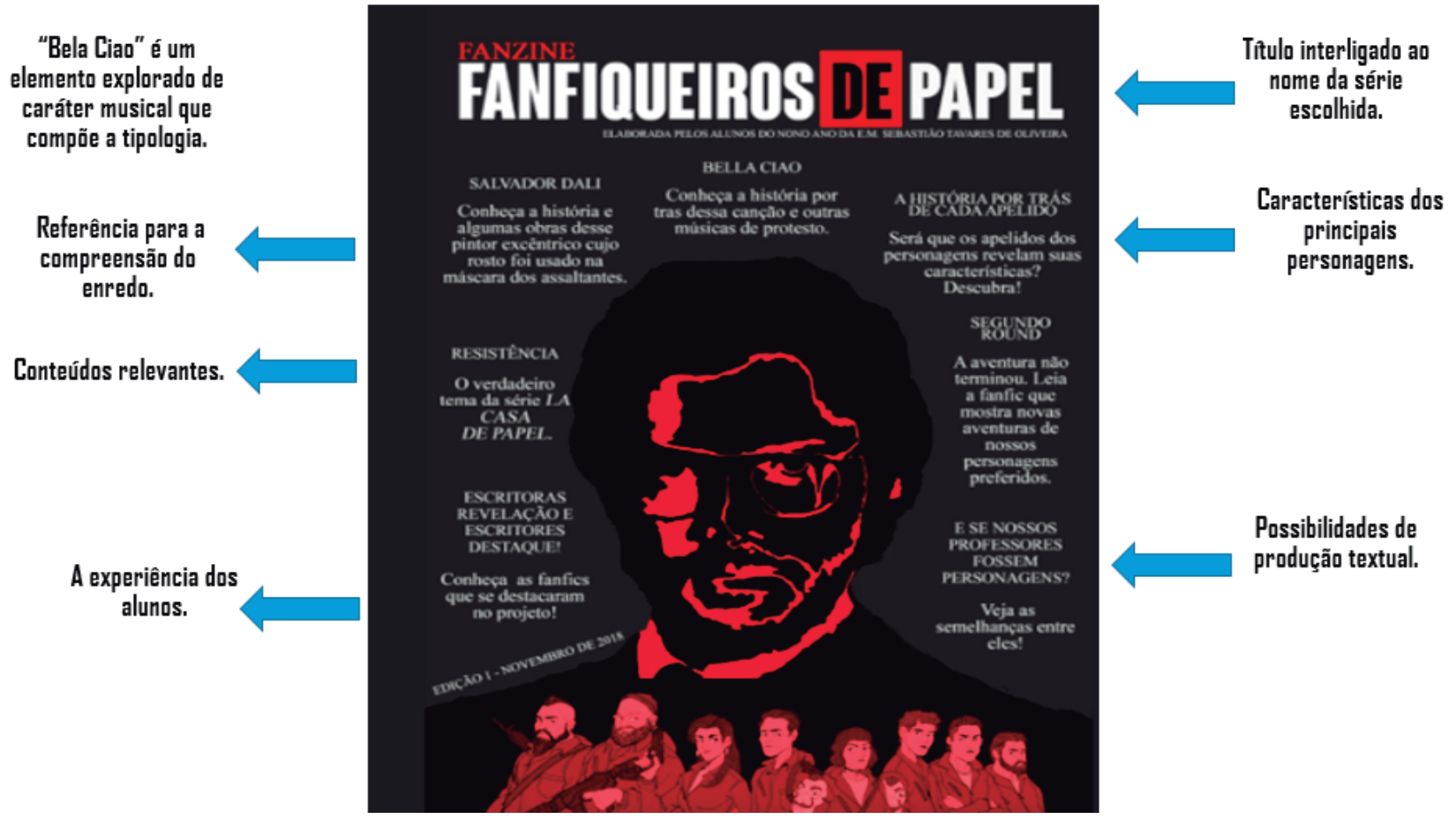

Fonte: Adaptado de Nova Escola (2020).

No entanto, o fanzine é de grande relevância em sua possibilidade de forma autônoma de produção na educação, manifestando artisticamente e culturalmente interesses particulares de expressão e criatividade. Apesar de não ser um gênero comum de encontrar, há pessoas que confeccionam e vendem suas produções pela internet.

\section{INFOGRÁFICO E SUA MODALIDADE DISCURSIVA}

O infográfico é um texto que se faz presente na internet, televisão e, ainda também nos meios impressos. Em sua composição verbal e não-verbal, ele pode ser composto por "mapas, fotografias, ilustrações, gráficos e outros recursos visuais" (FILHO, 2014, p. 33). Com esses recursos, permite-se que o leitor utilize antigas e novas informações para construir seu conhecimento. Porém, para que seja um bom infográfico, é de relevância manter uma autonomia discursiva, isto é, não necessariamente precisar recorrer a outros textos. Observe o exemplo de um infográfico complexo. 
Imagem 2 - Infográfico recontextualizado sobre sustentabilidade

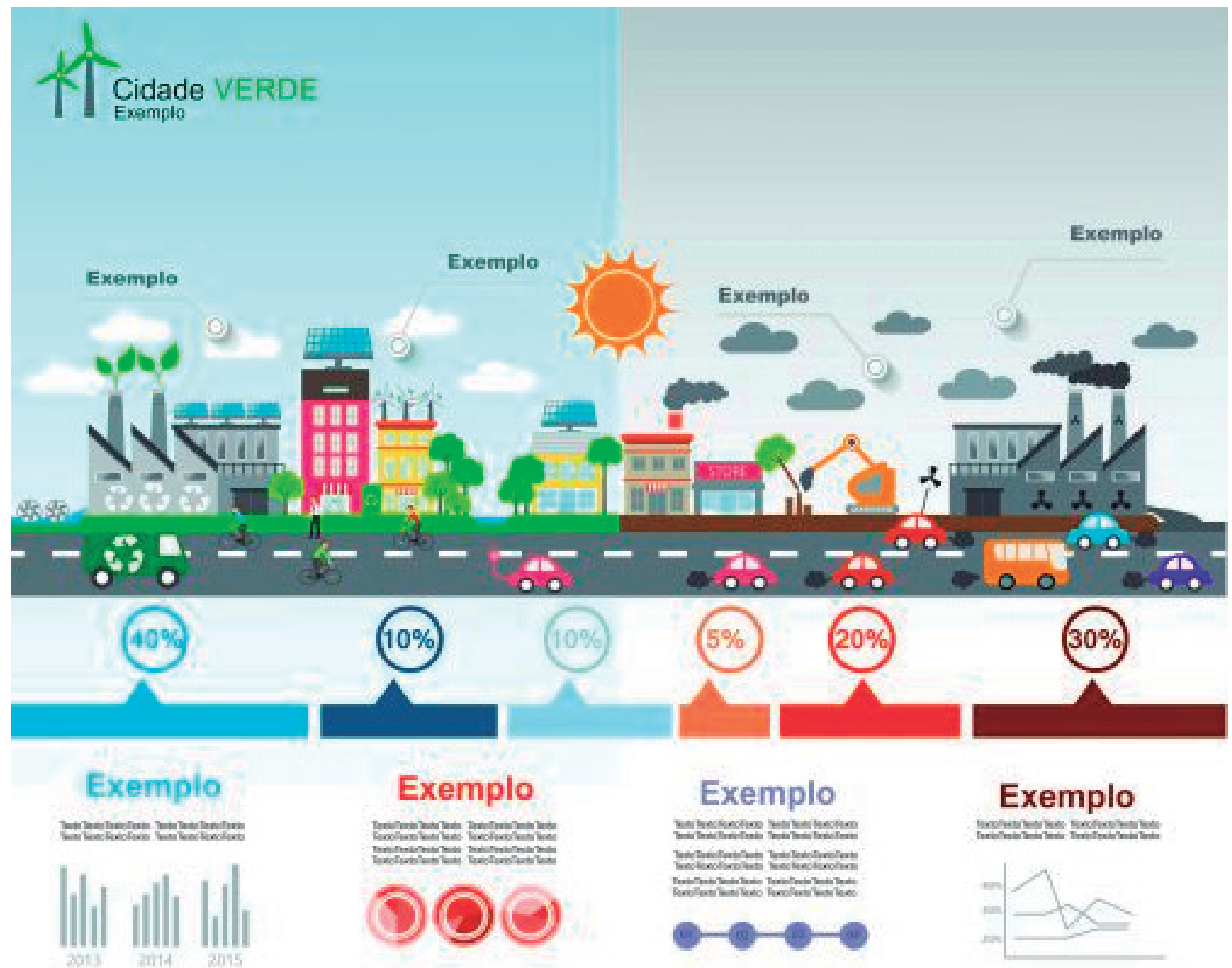

Fonte: Revista Cidade Verde (2019).

O infográfico apresentado na imagem 2 possui em sua abordagem uma categoria explicativa, em que "baseia-se em temáticas envolvendo causa e efeito, retrospectivos, antecipativos, passo a passo ou sobre fluxo de informações" (PELTZER, 1991, p. 42). Assim, para que um infográfico seja uma boa ferramenta educomunicativa, ele deve ser apresentado de modo organizado, facilitando a compreensão das informações nele contidas por diferentes níveis de pessoas, desde os técnicos até os leigos no assunto, por exemplo. Ademais, na leitura e produção desse gênero, há de se imaginar “[...] desde a percepção dos sinais gráficos e sua interpretação em som ou imagem mental até a transformação dessa ferramenta em ideias, provocando a geração de inferências, de reflexões, de analogias, de generalizações etc.” (COSCARELLI, 1999. p. 31).

Dessa forma, a apresentação gráfica do infográfico é muito importante para a sua correta interpretação e, também deve ser personalizado visualmente de acordo com o tipo de público-alvo a ser abordado, tema, área de atuação, entre outros. Enquanto ferramenta educomunicativa, um bom infográfico necessita de pesquisa sobre o assunto que será abordado para se montar um roteiro eficiente. 
Como tal gênero costuma ser composto por textos breves com figuras e imagens, é preciso selecionar o roteiro para que ele fique o mais objetivo possível.

\title{
PODCASTS: PRODUÇÃO E UTILIZAÇÃO
}

O formato desse gênero é bastante consolidado na internet como espaço de discussão aprofundada de diversos conhecimentos, sendo um podcast um "produto sonoro veiculado pela internet, de curta duração e sobre um determinado tema. Geralmente um trecho, uma reflexão, uma entrevista ou a locução de informações sobre um assunto específico (MICHALSKI et al., 2011, p. 7). Dessa forma, a utilidade de podcasts engloba mais que apenas o áudio gravado, pois seu formato está muito associado com um de blog e, são nessas características que se evidencia tal linguagem enquanto uma boa forma de trabalhar a educomunicação, pois

\begin{abstract}
é possível associar hipertextos e conteúdos externos acessados por hiperlinks; sua utilização não deve ser complexa; Conta com grande diversidade de locais em que podem ser hospedados gratuitamente; Sua organização é por postagens, ou episódios, que podem ser produzidos individualmente ou de forma coletiva; $\mathrm{O}$ acesso é de forma livre ou por meio de um registro específico; O público pode receber avisos das últimas atualizações ativando assinaturas ou notificações (PAULA, 2016, p. 15).
\end{abstract}

Para que essas características sejam enriquecidas, não deve haver elementos muito complexos no podcast, provendo uma comunicação direta e símbolos claros para que o ouvinte consiga alcançar seu objetivo principal, que é ouvir o programa. Observe um exemplo:

Imagem 3 - Programa focado em esportes outdoors

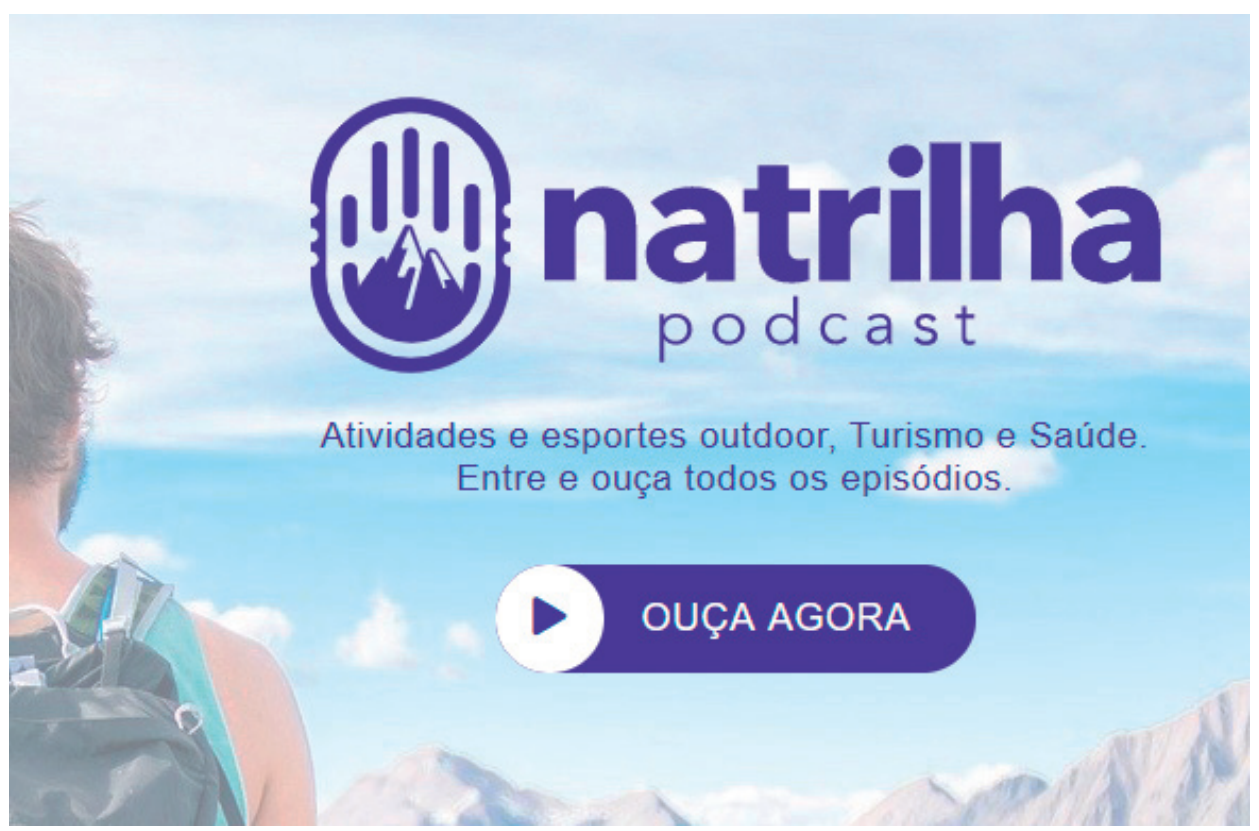

Fonte: Natrilha podcast (2019). 
Nesse formato de podcast, têm-se programas que contam, muitas vezes, com convidados externos para conversar sobre experiências, informações técnicas e dicas para ouvintes praticantes ou não desses esportes outdoors. É um podcast com o intuito de incentivo na prática regular de esportes. O podcast pode ser publicado facilmente por qualquer pessoa.

\section{HQ’s: UMA ESTÉTICA COMUNICATIVA}

A adoção das História em Quadrinhos (HQ’s) na educação eleva uma abertura da sociedade para variadas formas de ensino, utilizando-se de recursos que aproximem os alunos dos conteúdos trabalhados em aula. Em sua estrutura visual, esquemática e verbal, ou não, há uma série de possibilidades combinatórias e variações, sendo que

as HQ's ocupam papel de destaque no processo de adequação de uma linguagem técnica/ formal para uma linguagem imagética ao transcodificar uma linguagem formal/técnica/ textual para uma linguagem visual, proporcionando uma experiência mais ampla, seja tanto de leitura quanto de compreensão (SANTOS et al., 2017, p. 39).

Assim, nesse gênero, os docentes podem ter a experiência cognitiva transformadora e significativa para os seus alunos, pela produção de um meio de comunicação historicamente engajado nas causas sociais e de características notadamente particulares. Observe isso no exemplo:

Imagem 4 - Parte de uma História em Quadrinhos da Revista Recreio
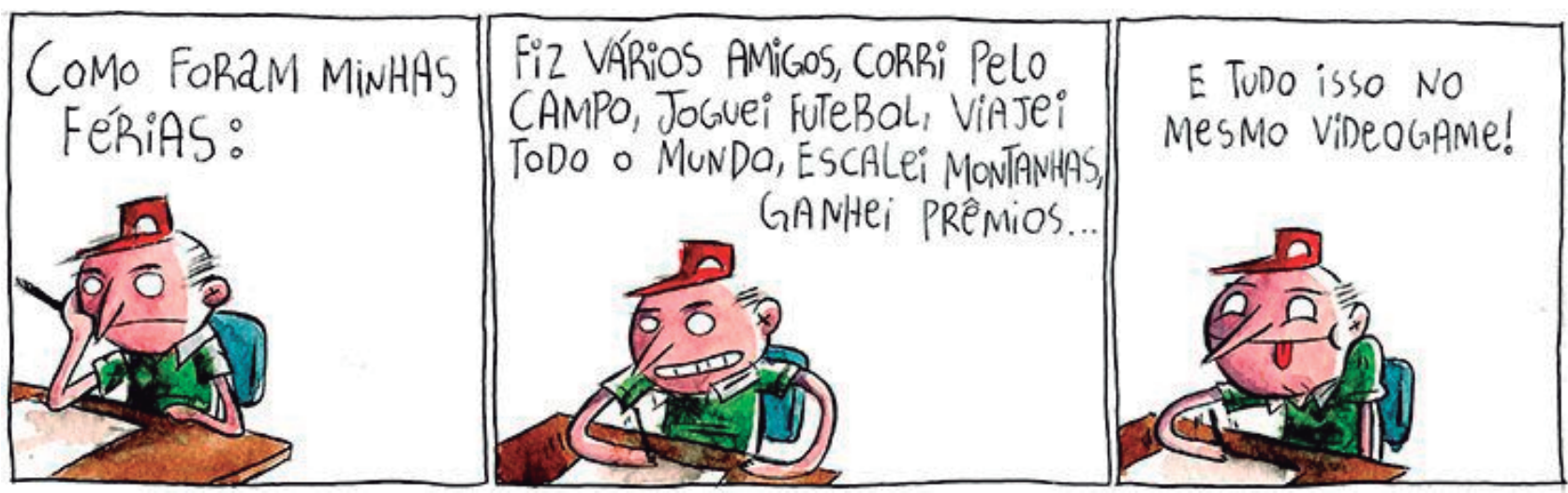

Fonte: Nova Escola (2020)

Nesse gênero textual, o processo de educomunicação ocorre na interação do personagem com o seu público, ou seja, os alunos. Soares (2014, p. 13), salienta que "as interações geram intervenções que fornecem compreensões postas em partilha no levantamento de problematizações". Assim sendo, no desempenho favorável enquanto ferramenta educomunicativa, os produtores devem utilizar diversos recursos gráficos nesse texto com o intuito de trazer o leitor para "dentro" da história contada, principalmente provocar um pensamento reflexivo e questionador acerca da realidade mundial, sempre trazendo um ponto de vista humanista sobre as situações. 


\section{CONSIDERAÇÕES FINAIS}

Favoravelmente, as linguagens dão sentido às mensagens trocadas nos processos comunicativos e é por meio delas que se aprende o mundo. No entanto, é de total relevância pesquisar os primórdios e evolução das ferramentas e plataformas educomunicativas no âmbito de aprimorar a formação de professores e alunos nas concepções pedagógicas contemporâneas em ambientes virtuais de ensino e aprendizagem.

Para isso, não basta utilizar computadores e programas nas escolas ou fora dela, é preciso ir além disso, criando situações de formação em conhecimentos, com acompanhamento e orientação continuada para provocar a autonomia crítica dos educandos. E, refletir esses recursos implica em insistência nas estratégias pedagógicas, pois além dessas opções existem muitas outras para serem discutidas, aprofundadas e praticadas.

A multimodalidade presente nas linguagens oral, escrita, audiovisual e multimídia facilitam a aprendizagem, fazendo com que o processo seja mais desafiador e sintonizado com a base sócio técnica e sociocultural de nossa sociedade. Portanto, deve-se sempre levar em consideração a necessidade de criar ambiências comunicativas nos centros de ensino e fora deles, visando práticas e/ou materiais que busquem melhorar os índices comunicativos, ou seja, elencar a educomunicação.

\section{REFERENCIAS}

BERGER, P. L. LUCKMANN, T. Os fundamentos do conhecimento na vida cotidiana: A construção social da realidade. Petrópolis, RJ: Vozes, 2003.

BRAGA, C. F. CIRINO, A. F. OLIVEIRA, M. L. S. Comunicação e mídia: interfaces com a cidadania e com a cultura. Goiânia: Gráfica UFG, 2017.

BUENO, T. Cultura da Convergência. Rev. Estud. Comum. 2. ed. São Paulo: Aleph; v. 12, n. 28, p. 183-186, ago., 2011.

CALIXTO, D. O. Memes na internet: Entrelaçamentos entre educomunicação, cibercultura e a "zoeira" de estudantes nas redes sociais. Escola de Comunicações e Artes. São Paulo, v. 4, n. 2, p. 1-234, jun., 2017.

CONGRESSO DE CIÊNCIAS DA COMUNICAÇÃO NA REGIÃO NORDESTE. BEZERRA et al. J. C. O. (org). Fanzine como ferramenta pedagógica educomunicativa. Intercom - Sociedade Brasileira de Estudos Interdisciplinares da Comunicação, n. 19, 2017, Salvador, 10 p. 
CONGRESSO DE CIÊNCIAS DA COMUNICAÇÃO NA REGIÃO NORDESTE. SILVA, et al.

A. S. (org). Ecossistemas educomunicativos: o blog como ferramenta educomunicativa. Intercom Sociedade Brasileira de Estudos Interdisciplinares da Comunicação, n. 15, 2015, Uberlândia, 16 p.

XXXIX CONGRESSO BRASILEIRO DE CIÊNCIAS DA COMPUTAÇÃO. CITELLI, A. (org). Educomunicação: temporalidades e sujeitos. Intercom - Sociedade Brasileira de Estudos Interdisciplinares da Comunicação, n. 16, 2016, São Paulo, 15 p.

COSCARELLI, C. V. Espaços hipertextuais. Anais do II Encontro Internacional Linguagem, Cultura e Cognição, jun. 2003, FAE - UFMG, BH. Coord.: Eduardo Fleury Mortimer, Ana Luiza B. Smolka.

COSTA, E. S. MATOS, R. L. Educomunicação e ação comunicativa na formação do sujeito leitor. Staes. v. 9, n. 15, 2019.

FILHO, C. M. Dicionário da comunicação. São Paulo: Editora Paulus, 2014.

FREIRE, P. Educação e mudança. 36. ed. Rio de Janeiro: Paz e Terra, 2014.

FREIRE, P. Pedagogia da autonomia: saberes necessários à prática educativa. 30. ed. São Paulo: Paz e Terra, 2004.

GAIA, R. V. Educomunicação \& mídias. Maceió: Ufal, 2001.

GASQUE, K C. G. D. Teoria Fundamentada: nova perspectiva à pesquisa exploratória. In: MUELLER, S. P. M. (Org.). Métodos para a pesquisa em Ciência da Informação. Brasília: Thesaurus, 2007. p. 83-118.

GÓMEZ, G. O. Educomunicação: recepção midiática, aprendizagens e cidadania. São Paulo: Paulinas, 2014.

GOMES, L. F. Hipertextos multimodais: leitura e escrita na era digital. Jundiaí: Paco Editorial, 2010.

KUROVSKI, C. Plataforma Youtube, produções independentes e educomunicação: possibilidades para um saber alternativo. Acervo Digital. Curitiba, v. 4, n. 18, 2015.

LIBÂNEO, J. C. O processo de ensino na escola. São Paulo: Cortez, 1994. 
MARTÍN-BARBERO, J. Desafios culturais da comunicação à educação. Revista Comunicação \& Educação, n. 18, p. 51-61, maio/ago, 2000.

MARTÍN-BARBERO, J. Dos meios às mediações: comunicação, cultura e hegemonia. Rio de Janeiro: UFRJ, 2009.

MARTINS, Gilberto de Andrade. Estudo de caso: uma estratégia de pesquisa. 2. ed. São Paulo: Atlas, 2008.

MICHALSKI, et al. Educomunicação: participação, conhecimento e cidadania. Paraná: SETI, 2011.

NAGAMINI, E. Práticas educativas e interatividade em Comunicação e Educação. Ilhéus, BA: Editus, 2016.

NATRILHA PODCAST. Esportes outdoors. [s.n.], Rio de Janeiro, n. 3, p. 1-4, 24 fev. 2018.

NOVA ESCOLA. Fanzines e educação. [s.n.], São Paulo, n. 24, p. 1-5, 17 de abr. 2020.

NOVA ESCOLA. Os blogs educativos. [s.n.], São Paulo, n. 5, p. 1-4, 08 de ou. 2018.

ORLANDI, E. P. Análise de discurso: princípios e procedimentos. 4. ed. São Paulo: Pontes, 2002.

PAULA, J. P. F. Ambientalidades: Jornalismo ambiental e educomunicação em podcast. Repositório. v. 3 , n. $11,2016$.

PELTZER, G. Periodismo iconográfico. Madrid: Rialp, 1991.

PEREIRA, B. G. et al. Concepções interdisciplinares sobre linguagem: dialogando com diferentes perspectivas do conhecimento. Revista São Luís Orione. v. 2, n. 13, 2018.

PORTAL COMUNICARE. Crítica cultural no Youtube. [s.n.], Paraná, n. 7, p. 1-2, 19 abr. 2020.

PRIMO, A. Interação mediada por computador: comunicação, cibercultura, cognição. Porto Alegre: Sulina, 2007.

REVISTA CIDADE VERDE. Significado de Infográfico. [s.n.], Piauí, n. 16, p. 1-3, 19 jan. 2020. 
SANTOS, C. Os fanzines como recurso didático de geografia no Parfor Pedagogia da UFRJ. In: SANTOS, C (org). As geografias periféricas e a periferia na geografia: olhares sobre a Baixada Fluminense. Nova Iguaçu: Agbook, 2016, p. 11-36.

SANTOS, et al. Educomunicação: Histórias em quadrinhos e fanzines no ensino de Artes. Comunicação \& Educação. v. 19, n. 1, 2017.

SILVA, A. C. B. A literatura na era digital. Anais do XII Congresso internacional da abralic: centro, centros - ética, estética. Curitiba: UFPR, 2011.

SOARES, D. Educomunicação - o que é isto? Instituto de Educação e Cultura. São Paulo, 2006.

SOARES, I. Mas, afinal, o que é Educomunicação. Portal do Núcleo de Comunicação e Educação da Universidade de São Paulo - USP, 2014.

SOARES, I. Educomunicação: o conceito, o profissional, a aplicação: Contribuições para a reforma de Ensino Médio. São Paulo: Paulinas Editora, 2012.

SOARES, I. Educomunicação e a formação de professores no século XXI. Revista FGV Online. v. 4, n. 1, 2014.

TEIXEIRA, A. R. HQ: traga o humor para as aulas de língua portuguesa. Nova Escola, São Paulo, n. 8 , p. $1-6,15$ maio 2020 .

THOMPSON, J. B. A mídia e a modernidade: uma teoria social da mídia. Petrópolis, RJ: Vozes, 1998. 